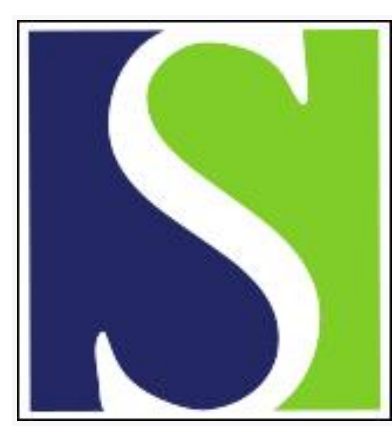

Scand J Work Environ Health 2000;26(4):346-352

https://doi.org/10.5271/sjweh.552

Issue date: Aug 2000

Failure to confi rm neurotoxic impairment using cerebral magnetic resonance imaging on solvent-exposed workers

by Aaserud O, Nakstad PH, Bakke SJ, Reinvang I,, Borchgrevink HM, Lie V, Malt UF, Gjerstad L

Key terms: basal ganglia; brain dysfunction; cerebral atrophy; occupational exposure; organic solvent

This article in PubMed: www.ncbi.nlm.nih.gov/pubmed/10994801

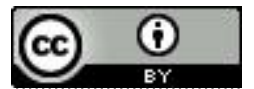




\title{
Failure to confirm neurotoxic impairment using cerebral magnetic resonance imaging on solvent-exposed workers
}

\author{
by Olaf Aaserud, MD, ${ }^{1}$ Per H Nakstad, MD, ${ }^{2}$ Søren J Bakke, MD, ${ }^{2}$ Ivar Reinvang, PhD, ${ }^{3}$ Hans M Borchgre- \\ vink, MD, ${ }^{4}$ Vemund Lie, MD, ${ }^{5}$ Ulrik F Malt, MD, ${ }^{3}$ Leif Gjerstad, $M D^{1}$
}

\begin{abstract}
Aaserud O, Nakstad PH, Bakke SJ, Reinvang I, Borchgrevink HM, Lie V, Malt UF, Gjerstad L. Failure to confirm neurotoxic impairment using cerebral magnetic resonance imaging on solvent-exposed workers. Scand $J$ Work Environ Health 2000;26(4):346-352.

Ohjectives The study aimed at assessing signs of nervous system impairment by cerebral magnetic resonance imaging (MRI) among workers with a history of long-term exposure to mixtures of organic solvents.

Methods Thirty-six workers (mean age 44.1 years) with at least 10 (mean 23.9) years of occupational exposure to solvents and pair-matched referents with no former solvent exposure went through a blind, random-order investigation of cerebral MRI, performed with a 1.5-tesla scanner.

Results Linear measurements of the MRI tomograms showed a slight tendency toward wider ventricles and broader cortical sulci in the reference group. Visual evaluation of the MRI by 2 experienced neuroradiologists showed no significant difference between the groups; however, there was substantial interobserver variability. Conclusions The MRI findings of this study do not support the hypothesis that long-term low-level occupational exposure to organic solvents results in the development of brain atrophy, or specific MRI signal changes in the region of the basal ganglia and thalami.
\end{abstract}

Key terms basal ganglia, brain dysfunction, cerebral atrophy, occupational exposure, organic solvents.

Evidence of chronic toxic encephalopathy has been reported in several studies on patients with former occupational exposure to mixtures of organic solvents (14). Some investigators have also described pathological MRI (magnetic resonance imaging) changes in patients with solvent-induced toxic encephalopathy $(5,6)$.

The appearance of clinical cases raises the concern that there may exist a residue of subclinical cases representing a "hidden part of the iceberg" (7).

In addition, neuropsychological abnormalities have been demonstrated in groups of still-active, solvent-exposed workers $(8,9)$. We wanted to explore whether there also exists any lesion attributable to solvent exposure in cerebral MRI in a group of still-active, solvent-exposed workers for whom a neuropsychological examination had shown modest, though significant, differences when they were compared with pair-matched referents (10).

\section{Subjects and methods}

\section{Subjects and exposure}

The study included 36 male workers from 5 Norwegian military camps who had been exposed to mixtures of organic solvents for more than 10 years, and 36 age, gender, and educationally pair-matched referents from the same camps who had not been occupationally exposed to solvents. Persons with a history of alcohol or drug dependence, cerebral infectious disease, cerebral trauma

1 Department of Neurology, Rikshospitalet, University of Oslo, Oslo, Norway.

2 Department of Neuroradiology, Rikshospitalet, University of Oslo, Oslo, Norway.

3 Department of Psychosomatic Medicine, Rikshospitalet, University of Oslo, Oslo, Norway.

4 HQ Defence Command Norway, The Joint Medical Service, Oslo, Norway.

5 The Occupational Health Service, Rygge Main Air Station, Rygge, Norway.

Reprint requests to: Dr Olaf Aaserud, Department of Neurology, Rikshospitalet, N-0027 Oslo, Norway. [E-mail: olaf.aaserud@rikshospitalet.no] 
Table 1. Demographic data of the study groups. No significant difference was found between the groups. (SEM = standard error of the mean, AUDIT $=$ Alcohol Use Disorders Identification Test)

\begin{tabular}{|c|c|c|c|c|c|c|c|c|c|c|c|c|c|c|}
\hline \multirow[t]{2}{*}{ Group } & \multicolumn{3}{|c|}{$\begin{array}{c}\text { Age } \\
\text { (years) }\end{array}$} & \multicolumn{2}{|c|}{$\begin{array}{l}\text { Education } \\
(\text { scores } 0-1)^{a}\end{array}$} & \multicolumn{2}{|c|}{$\begin{array}{l}\text { Systolic blood } \\
\text { pressure (mmHg) }\end{array}$} & \multicolumn{3}{|c|}{$\begin{array}{l}\text { Diastolic blood } \\
\text { pressure }(\mathrm{mmHg})\end{array}$} & \multicolumn{2}{|c|}{$\begin{array}{l}\text { Alcohol } \\
\text { index }\end{array}$} & \multicolumn{2}{|l|}{$\begin{array}{l}\text { AUDIT } \\
\text { score }\end{array}$} \\
\hline & Mean & SEM & Range & Mean SEM & Range & Mean SEM & Range & Mean & SEM & Range & Mean SEM & Range & Mean SEM & Range \\
\hline Exposed workers & 44.1 & 1.3 & $28-57$ & 0.2 & & $140.8 \quad 2.8$ & $120-195$ & 89.6 & 1.7 & & $10.0 \quad 1.1$ & $0-24$ & $4.0 \quad 0.4$ & $0-10$ \\
\hline Referents & 44.9 & 1.3 & $30-57$ & 0.1 & $0-1$ & 141.32 .6 & $115-185$ & 91.7 & 1.5 & $75-120$ & 13.41 .4 & $1-34$ & $4.2 \quad 0.4$ & $0-10$ \\
\hline
\end{tabular}

a $0=$ lower level (primary school, officer's training school); 1 = higher level (technical school, high school, war college, university).

$b \sum_{i=1}^{n} a_{i} b_{i}$, where $n=$ number of periods (10 years each) with alcohol consumption, $a=$ frequency of drinking during each 10 -year period, $b=a$ cohol consumption on a typical drinking day.

severe enough to cause hospitalization, current disease of the central nervous system, or diabetes mellitus were not taken into the study. To avoid complications during the MRI, persons with intracorporal metal were also not included. A blind, random-order study design was used, and all the MRI pictures were examined by the same investigators.

The exposed workers had not been exposed to solvents less than 2 days prior to the investigations. The participants were tested for alcohol in respiratory air on the day of the examinations, and this test was negative for all the participants. For further control for possible alcohol dependence among the participants, an index of alcohol use was calculated; it reflected the frequency and amount of alcohol intake through the years for each of the participants [formula: alcohol index $=\sum_{i=1}^{n} a_{i} b_{i}$, where $\mathrm{N}=$ number of periods ( 10 years each) with alcohol consumption, $a=$ frequency of drinking during each 10-year period, $b=$ alcohol consumption on a typical drinking day]. Three to four drinks 3 times a month during 30 years corresponds to an alcohol index of 12 . To evaluate the actual alcohol use, we employed the alcohol-specific part of the Alcohol Use Disorders Identification Test (AUDIT) (11). In AUDIT, a score of $\geq 11$ is regarded as indicative of an increased risk of a alcohol-use disorder. Demographic data of the groups are presented in table 1.

The workers had performed a variety of tasks, among which degreasing, spray and brush painting, engine disassembling, and gluing were the most common. They had been exposed to several organic solvents through work for present and former employers (table 2). The mean duration of solvent exposure was 23.9 (standard error of the mean 1.3, range $11-37$ ) years. As an attempt to obtain an indirect indicator of the significance of the exposure, an index of acute effects of exposure was calculated. The exposed workers were asked to indicate the occurrence of symptoms of possible intoxication during the exposure. The symptoms were weighted with respect to the relative intensity of exposure estimated as causative [no symptoms $=0$, slight irritation of the eyes or nose $=1$, strong irritation (coughing or nausea) $=2$, vertigo or dizziness $=3$, inebriation $=4$ ], and the scores for each 5 years of exposure were summed to make the index of acute
Table 2. Level of exposure of the exposed workers to solvents during present and former employments. ( $\mathrm{N}=$ number of workers)

\begin{tabular}{|c|c|c|c|c|c|c|}
\hline \multirow[t]{3}{*}{ Solvent } & \multicolumn{6}{|c|}{ Level of exposure } \\
\hline & \multicolumn{3}{|c|}{ Years $<4$ hours/week } & \multicolumn{3}{|c|}{ Years $\geq 4$ hours/week } \\
\hline & $\mathrm{N}$ & Median & Range & $\mathrm{N}$ & Median & Range \\
\hline White spirit & 19 & 19 & $2-37$ & 21 & 15 & $1-35$ \\
\hline Thinner & 13 & 25 & $3-35$ & 13 & 13 & $1-32$ \\
\hline Fuel & 10 & 18.5 & $1-37$ & 10 & 25.5 & $8-35$ \\
\hline Trichloroethylene & 8 & 9 & $2-35$ & 5 & 19 & $2-34$ \\
\hline Acetone & 9 & 16 & $2-20$ & 1 & 3 & - \\
\hline
\end{tabular}

effects. The mean value of this index was 6.1 (standard error of the mean 0.8 , range $0-20$ ).

\section{Investigational methods}

The MRI investigations were carried out with a 1.5-tesla scanner (Magnetom, Siemens, Germany). Sagittal $T_{1}$ - and axial $\mathrm{T}_{2}$-weighted and proton-weighted images with a 5$\mathrm{mm}$ slice thickness and $2.5-\mathrm{mm}$ interspaces were performed in all. The matrix size was $192 \times 256$, and the field of view was $250 \mathrm{~mm}$. The $\mathrm{T}_{1}$-weighted images were done with 2 acquisitions, repetition time/echo time (TR/ $\mathrm{TE}$ ) $=600 / 15$ milliseconds (proton) and also with 1 acquisition, TR/TE $=3100 / 15-90$ milliseconds. One exposed subject and one referent dropped out because of claustrophobia. For the same reason, only sagittal $\mathrm{T}_{1}$-weighted images were obtained from another of the referents. Hence, for this person, only a few parameters could be analyzed. Two experienced neuroradiologists, who had both been working with MRI regularly for several years, independently evaluated the recordings with respect to atrophy, hyperintensities, and other pathological processes. The following rating scale was employed: $0=$ no, $1=$ slight, $2=$ moderate, and $3=$ pronounced abnormality. Both examiners were ignorant of the colleague's assessment, and they were also blinded with respect to the exposure data and the results of the other examinations of the subjects. At a later stage, the MRI recordings were reexamined with special attention to the occurrence of hypodensities in the basal ganglia and loss of grey-white matter discrimination. By this time, only $34 \mathrm{MRI}$ 
recordings were available for examination in each group. One of the neuroradiologists also performed linear measurements of cerebral sulcal and ventricular widths, as well as the widths of cerebellar fissures. The largest frontal, temporal, and parietal sulcus was measured in each subject. Care was taken to omit sulci that had been obliquely sliced; hence the measurements were made from slices below the convexity of the brain. Cerebellar fissures were also measured. Because of individual variations in cerebellar anatomy and methodological limitations making the individual identification of fissures impossible, the 3 largest fissures of the upper half of the vermis were measured, and the sum was employed for further statistics. Adequate recordings of the cerebellum were lacking for 1 referent. In the lateral ventricles the largest width of each temporal horn was measured, as well as the distance between the septum pellucidum and the right and the left caudate nucleus and the distance between the anterior horns. Finally, the width of the left temporal horn was measured (figure 1).

\section{Statistical methods}

Continuous variables with an approximate normal distribution were compared using a 2-sampled Student's
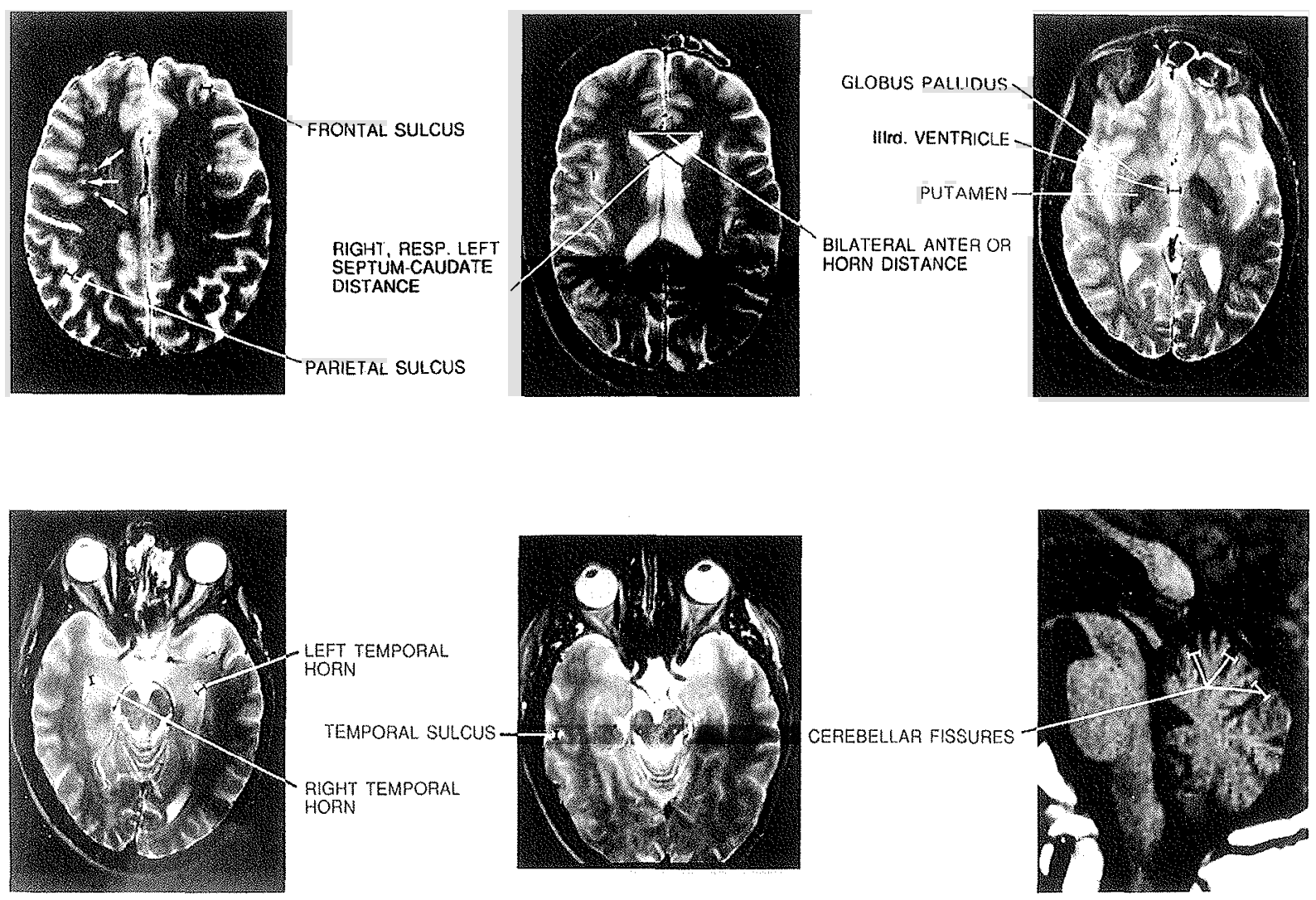

Figure 1. Illustration of magnetic resonance imaging (MRI) of the sites of the measurements and an example of tomograms showing hyperintensities (arrows) and the location of the globus pallidus and putamen.

Table 3. Sulcal and ventricular measures in magnetic resonance images from the exposed workers and the referents. (SEM $=$ standard error of the mean)

\begin{tabular}{|c|c|c|c|c|c|c|c|c|c|c|c|c|c|c|c|c|c|c|c|}
\hline \multirow[t]{3}{*}{ Group } & \multicolumn{8}{|c|}{ Sulcal width (mm) } & \multicolumn{11}{|c|}{ Ventricular measures (mm) } \\
\hline & \multicolumn{2}{|c|}{ Frontal } & \multicolumn{2}{|c|}{ Temporal } & \multicolumn{2}{|c|}{ Parietal } & \multicolumn{2}{|c|}{$\begin{array}{l}\text { Cerebellum, } \\
3 \text { fissures }\end{array}$} & \multicolumn{2}{|c|}{$\begin{array}{l}\text { Bilateral } \\
\text { anterior } \\
\text { horn } \\
\text { distance }\end{array}$} & \multicolumn{2}{|c|}{$\begin{array}{c}\text { Left } \\
\text { septum- } \\
\text { caudatus } \\
\text { distance }\end{array}$} & \multicolumn{2}{|c|}{$\begin{array}{l}\text { Right } \\
\text { septum- } \\
\text { caudatus } \\
\text { distance }\end{array}$} & \multicolumn{2}{|c|}{$\begin{array}{c}\text { Left } \\
\text { temporal } \\
\text { horn }\end{array}$} & \multicolumn{2}{|c|}{$\begin{array}{l}\text { Right } \\
\text { temporal } \\
\text { horn }\end{array}$} & \multirow{2}{*}{$\begin{array}{c}\text { 3rd } \\
\text { ventricle }\end{array}$} \\
\hline & Mean & SEM & Mean & SEM & Mean & SEM & Mean & SEM & Mean & SEM & Mean & SEM & Mean & SEM & Mean & SEM & Mean & SEM & \\
\hline Exposed & 3.1 & 0.1 & 2.8 & 0.1 & 4.0 & 0.2 & 7.8 & 0.2 & 34.9 & 0.4 & 10.5 & 0.5 & 9.8 & 0.4 & 3.1 & 0.2 & 3.6 & 0.2 & $5.8 \quad 0.3$ \\
\hline Referents & 3.8 & 0.2 & 3.2 & 0.1 & 4.5 & 0.2 & 7.7 & 0.3 & 35.4 & 0.5 & 11.8 & 0.5 & 10.8 & 0.5 & 3.6 & 0.3 & 4.4 & 0.5 & $\begin{array}{ll}5.7 & 0.3\end{array}$ \\
\hline P-value & \multicolumn{2}{|c|}{0.01} & \multicolumn{2}{|c|}{0.03} & \multicolumn{2}{|c|}{0.08} & \multicolumn{2}{|c|}{0.86} & \multicolumn{2}{|c|}{0.48} & \multicolumn{2}{|c|}{0.05} & \multicolumn{2}{|c|}{0.17} & \multicolumn{2}{|c|}{0.21} & \multicolumn{2}{|c|}{0.36} & 0.92 \\
\hline
\end{tabular}


t-test. A Wilcoxon 2-sample test was employed to compare data not falling into this category. Tests for correlations were carried out with Spearman's rank correlation test.

\section{Results}

The numerical measurements of the cerebral ventricles, cortical sulci, and cerebellar fissures in the MRI recordings did not show any exposure-related atrophy among the exposed workers when they were compared with the referents (table 3 ). On the contrary, there was a tendency towards larger lateral ventricles and sulci among the referents; these findings were of statistical significance for the frontal and temporal sulci and the left septumcaudate distance.

On visual evaluation (table 4), one neuroradiologist gave $23 \%$ of the exposed workers a rating of general cortical atrophy and for the other neuroradiologist the corresponding figure was $17 \%$. For the referents the corresponding figures were $29 \%$ and $40 \%$. Atrophy was mostly classified as "slight". One examiner found significantly more generalized cortical atrophy and a higher frequency of white-matter hyperintensities in the reference group. Both examiners found several subjects with hypodensity in the putamen or globus pallidus, but there was no significant difference between the exposed workers and the referents. Neither did grey-white-matter discrimination differ between the groups.

One of the exposed subjects had white-matter hyperintensities classified by neuroradiologist 1 as "pronounced" and by the other as "moderate". The hyperintensities were mostly arranged periventricularly and, especially in the centrum semiovale, bilaterally, and they were considered to be of ischemic origin. This man was 35 years old with 17 years of exposure to solvents, but he had a symptom index of 0 and a low alcohol index (4). One of the referents had some cerebral atrophy, atrophy of the cerebellar vermis, and an enlarged cisterna magna; the abnormalities were classified as "moderate" by neuroradiologist 1 and as "pronounced" by neuroradiologist 2.

No correlation was found between any of the MRI parameters and the exposure time or the index of acute effects; neither was there any correlation with systolic or diastolic blood pressure. General cortical atrophy, as estimated by neuroradiologist 1 , correlated with age in both groups $(\rho=0.371, P=0.03$, in the exposed groups and $\rho=0.428, P=0.01$, in the reference group). There was also a positive correlation between the 3 rd ventricle width and age $(\rho=0.479, P=0.01)$ for the referents. A negative correlation was found between the bilateral anterior horn distance and the alcohol index $(\rho=-0.416, P=0.02)$ of the exposed group.
Table 4. Results of the magnetic resonance imaging (MRI) of the exposed workers and referents. ${ }^{a}$

\begin{tabular}{|c|c|c|c|c|c|c|}
\hline \multirow{2}{*}{ MR| resilita } & \multicolumn{3}{|c|}{ Examiner 1} & \multicolumn{3}{|c|}{ Examiner 2} \\
\hline & $\begin{array}{l}\text { Ex- } \\
\text { posed } \\
(\mathrm{N})\end{array}$ & $\begin{array}{c}\text { Refer- } \\
\text { ents } \\
(\mathrm{N})\end{array}$ & $\begin{array}{c}\mathrm{P}_{-} \\
\text {value }\end{array}$ & $\begin{array}{c}\text { Ex- } \\
\text { posed } \\
(\mathrm{N})\end{array}$ & $\begin{array}{l}\text { Refer- } \\
\text { ents } \\
\text { (N) }\end{array}$ & $\begin{array}{c}\mathrm{P} . \\
\text { value }\end{array}$ \\
\hline \multicolumn{7}{|l|}{ General cortical atrophy } \\
\hline No abnormality & 27 & 25 & 0.59 & 29 & 21 & 0.02 \\
\hline Slight abnormality & 8 & 10 & & 6 & 9 & \\
\hline Moderate abnormality & - & - & & - & 5 & \\
\hline Pronounced abnormality & - & - & & - & - & \\
\hline \multicolumn{7}{|l|}{ Focal cortical atrophy } \\
\hline No abnormality & 33 & 33 & 1.00 & 32 & 33 & 0.64 \\
\hline Slight abnormality & 2 & 2 & & 2 & 2 & \\
\hline Moderate abnormality & - & - & & 1 & - & \\
\hline Pronounced abnormality & - & - & & - & - & \\
\hline \multicolumn{7}{|l|}{ General central atrophy } \\
\hline No abnormality & 30 & 28 & 0.54 & 30 & 26 & 0.24 \\
\hline Slight abnormality & 5 & 7 & & 5 & 9 & \\
\hline Moderate abnormality & - & - & & - & . & \\
\hline Pronounced abnormality & - & - & & - & - & \\
\hline \multicolumn{7}{|c|}{ White-matter hyperintensity(les) } \\
\hline No abnormality & 31 & 30 & 0.82 & 31 & 24 & 0.04 \\
\hline Slight abnormality & 1 & 4 & & 4 & 10 & \\
\hline Moderate abnormality & 2 & 1 & & - & 1 & \\
\hline Pronounced abnormality & 1 & - & & - & - & \\
\hline \multicolumn{7}{|l|}{$\begin{array}{l}\text { Putaminal or globus pallidus } \\
\text { hypodensity }\end{array}$} \\
\hline No abnormality & 19 & 17 & 0.65 & 27 & 23 & 0.26 \\
\hline Slight abnormality & 14 & 16 & & 7 & 10 & \\
\hline Moderate abnormality & 1 & 1 & & $\cdot$ & 1 & \\
\hline Pronounced abnormality & - & - & & - & - & \\
\hline \multicolumn{7}{|l|}{$\begin{array}{l}\text { Decreased grey-white matter } \\
\text { discrimination }\end{array}$} \\
\hline No abnormality & 31 & 26 & 0.10 & 34 & 32 & 0.16 \\
\hline Slight abnormality & 3 & 8 & & - & 2 & \\
\hline Moderate abnormality & - & - & & - & - & \\
\hline Pronounced abnormality & - & - & & - & - & \\
\hline
\end{tabular}

a Rating scale: no abnormality $=0$, slight abnormality $=1$, moderate abnormality $=2$, pronounced abnormality $=3 ; N=35$ in both groups, except for the examination of density in the putamen or globus pallidus and grey-white discrimination, for which 34 magnetic resonance images were available in each group.

There was good agreement between the 2 neuroradiologists concerning the numbers of participants with signs of atrophy in the MRI (table 4). Both of them found relatively more abnormalities among the referents. Comparison at the individual level, however, showed relatively substantial interobserver differences in the assessment of atrophy, as well as differences in the signal abnormalities and differentiation between grey and white matter (figure 2).

\section{Discussion}

Our study represents the first controlled study to include MRI of still-active, solvent-exposed workers. There exist some case reports on cerebral MRI atrophy in patients who have been exposed to solvents in their occupation 


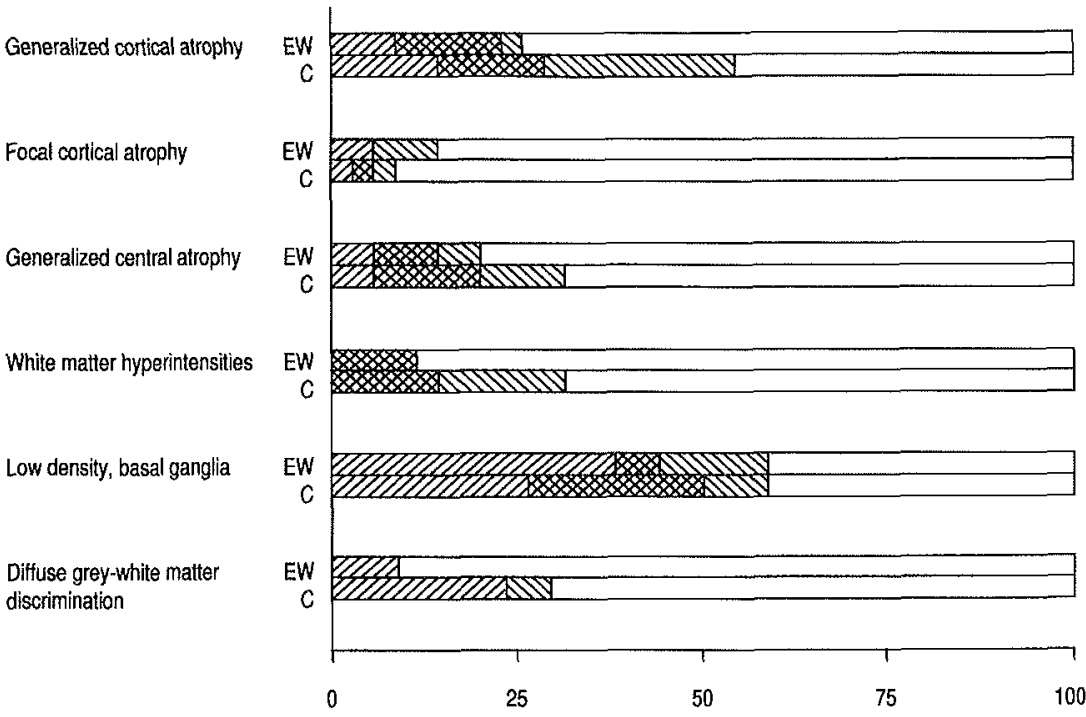

$\square$ Percentage share of exposed workers (EW), resp. controls $(C)$ in whom only neuroradiologist 1 made findings

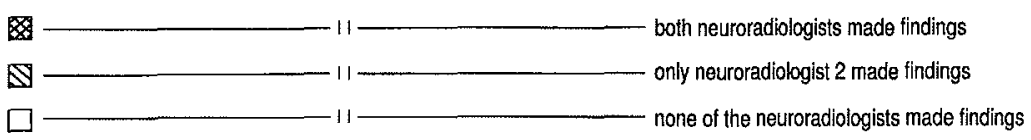

Figure 2. Comparison of the 2 neuroradiologists' diagnostic evaluations. Abnormalities rated as in table 4 . [EW $=$ exposed workers, $\mathrm{C}=$ controls (referents)]
$(12,13)$. In addition, in a German study of workers with previous exposure to tetrachloroethylene, signs of cerebral atrophy were reported for 12 of 13 patients (14). In another study, comparing cerebral computed tomography (CT) and MRI for 9 patients with occupational organicsolvent-induced encephalopathy, more frequent findings of central and cortical atrophy were reported when the latter method was employed (5). Lundberg et al (15) found no significant difference between MRI recordings from 15 formerly heavily exposed painters and a reference group of carpenters. Finally, in a controlled study of patients with symptoms of the central nervous system indicating chronic solvent intoxication, Thuomas et al (6) reported cerebral or cerebellar MRI atrophy in 20 out of 32 patients, while none of the 40 matched referents displayed such abnormalities.

In our study, comparing a working population with referents, one might not have expected to find large differences between the groups. However, as neuropsychological tests showed relative impairment on some tests regarding psychomotor speed, learning, and memory among the exposed workers when they were compared with the referents (10), it should also be relevant to search for signs of structural brain changes. Rather surprisingly, there was a tendency toward more MRI abnormalities among the referents than among the exposed subjects. Similar findings have also been made by 2 other groups using cerebral CT $(8,16)$. In their study of industrial painters, Elofsson et al (8) discussed this phenomenon as possibly caused by an increase in brain volume - a low-grade brain edema - in their solvent-exposed group.
They also speculated as to whether this finding is a prelude of developing degenerative characteristics. Anyhow, there is reason to be careful when such slight morphological MRI deviations are interpreted. As pointed out by Lundberg et al (15), metabolic factors and the hydration of the brain may also greatly influence its volume.

There are numerous reports on central and cortical atrophy in alcoholics $(17,18)$. To avoid this confounder, several measures had been taken to explore former and present alcohol use in the groups. There was no correlation between alcohol consumption and the MRI findings in either of the groups, except for a negative correlation with bilateral anterior horn distance in the exposed group.

In both groups, there was a relatively large incidence of slight atrophy and white-matter hyperintensities. Compared with reference values for cerebral CT (19), the mean measures of ventricular size were larger in our groups, but the level of significance for this cannot be calculated from the accessible data. However, because of methodological differences and differences in imaging quality between CT and MRI, a systematic error may have played some part in this comparison. We have not succeeded in finding complete and comparable reference values for MRI examinations, but the bilateral anterior horn distance and $3 \mathrm{rd}$ ventricle width in our groups did not differ significantly from those of a reference population $(\mathrm{N}=20)$ aged $31-50$ years when examined with MRI by Hayakawa et al (17). The hyperintensities described for both groups in our study were mostly classified as "slight". Hyperintensities of small caliber are known to occur to some extent in MRI recordings from 
asymptomatic persons, but more frequently with increasing age or the coexistence of cerebrovascular risk factors (20). Some of them probably represent perivascular Virchow-Robin spaces.

It could be argued that the reliability of the type of measurements performed in this study could be low. To keep the accuracy and reproducibility of the measurements as high as possible, special care had been taken to select cortical sulci and perform MRI measurements in a standardized and completely blind way. For the same reason, all the measurements were done by the same neuroradiologist (PHN). Still, linear measurements of sulci and ventricles will always be prone to some variability, but such variability should be expected to weaken rather than increase the statistical differences between the 2 groups. Volumetric methods may prove to be more rewarding in future studies.

Loss of discrimination between grey and white matter and a low signal in $\mathrm{T}_{2}$-weighted images of the basal ganglia (especially the putamina and globus pallidus) and thalami seem to be characteristic features of MRI recordings from toluene abusers with toxic encephalopathy $(21-23)$. Thuomas et al (6) reported a high frequency of similar findings in a group of patients with symptoms of chronic intoxication from occupational exposure to mixtures of solvents. A lower frequency of such deviations among the exposed workers in our study was not unexpected since they were not a group of patients. A similar picture among the referents, however, is more likely to reflect the inaccuracy of this sort of visual estimation from standard MRI recordings.

In clinical diagnostics, visual evaluation is the method for evaluating MRI recordings. Even though both neuroradiologists found about the same number of cases with atrophy in our study, further comparisons show some disagreement at the level of individual diagnoses (figure 2). Hence, $54 \%$ of the referents were given a diagnosis of either slight or moderate general cortical atrophy, but as few as $14 \%$ were given this assessment from both neuroradiologists. In addition, diversity exists concerning the diagnosis of white-matter hyperintensities among the referents. This variation illustrates the subjectivity of visual evaluations. Another group (24) studying cerebral atrophy in Alzheimer's disease has shown similar interrater disagreement for interpreting MRI findings. In clinical practice at our hospital, MRI scans and radiographs are always assessed by 2 radiologists. In this way the effect of interobserver differences should be reduced. Still, however, we think that the demonstrated disagreement emphasizes the lack of a clear-cut delimitation between the clinical classifications "no pathology" and "slight atrophy" in MRI diagnostics.

Unless further research can confirm the report (6) that signal aberrations also occur in the midbrain as a consequence of occupational exposure, MRI, and also CT, will probably still have its greatest importance for differential diagnostics in cases of suspected work-related solvent-induced encephalopathy.

\section{Concluding remarks}

Cerebral degenerative changes to a degree detectable by MRI scanning were not demonstrated in this study of solvent-exposed workers.

\section{Acknowledgments}

This work was supported by grants from The Occupational Research Fund of Statoil Norge AS and The Norwegian Research Council for Science and the Humanity.

\section{References}

1. Husman $\mathrm{K}$, Karli P. Clinical neurological findings among car painters exposed to a mixture of organic solvents. Scand $J$ Work Environ Health 1980;6:33-9.

2. Juntunen J, Antti-Poika M, Tola S, Partanen T. Clinical prognosis of patients with diagnosed chronic solvent intoxication. Acta Neurol Scand 1982,65:488-503.

3. Edling C, Ekberg K, Ahlborg G, Alexandersson R, Barregård L, Ekenvall L, et al. Long term follow up of workers exposed to solvents. Br J Ind Med 1990;47:75-82.

4. Morrow LA, Ryan CM, Hodgson MJ, Robin N. Risk factors associated with persistence of neuropsychological defictis in persons with organic solvent exposure. J Nerv Ment Dis 1991; 179:540-5.

5. Leira HL, Myhr G, Nilsen G, Dale LG. Cerebral magnetic resonance imaging and cerebral computerized tomography for patients with solvent-induced encephalopathy. Scand J Work Environ Health 1992;18:68-70.

6. Thuomas K- $\AA$, Möller C, Ödkvist LM, Flodin U, Dige N. MR imaging in solvent-induced chronic toxic encephalopathy. Acta Radiol 1996;37:177-9.

7. White RF, Proctor SP, Echeverria D, Schweikert J, Feldman RG. Neurobehavioral effects of acute and chronic mixedsolvent exposure in the screen printing industry. Am J Ind Med 1995;28:221-31.

8. Elofsson S-A, Gamberale F, Hindmarsh T, Iregren A, Isaksson A, Johnsson I, et al. Exposure to organic solvents: a crosssectional epidemiologic investigation on occupationally exposed car and industrial spray painters with special reference to the nervous system. Scand J Work Environ Health 1980;6:239-73.

9. Mikkelsen S, Jørgensen M, Browne E, Gyldensted C. Mixed solvent exposure and organic brain damage: a study of painters. Acta Neurol Scand 1988;78 suppl 118:1-143.

10. Reinvang I, Borchgrevink HM, Aaserud O, Lie V, Malt UF, Nakstad P, et al. Neuropsychological findings in a non-clinical sample of workers exposed to solvents. J Neurol Neurosurg Psychiatr 1994;57:614-6.

Scand J Work Environ Health 2000, vol 26, no 4 
11. Babor T, Fuente R de la, Saunders J, Grant M. AUDIT - the Alcoholism Use Disorders Identification Test: guidelines for use in primary health care. Geneva: World Health Organization, 1989. WHO/MNH/DAT/89.4.

12. Bernsen HJJA, Verhagen WIM, deBij1 MAO, Heerschap A. Magnetic resonance studies on brain dysfunction induced by organic solvents. Acta Neurol Belg 1992;92:207—14.

13. Welch L, Kirshner H, Heath A, Gilliland R, Broyles S. Chronic neuropsychological and neurological impairment following acute exposure to a solvent mixture of toluene and methyl ethyl ketone (MEK). Clin Toxicol 1991;29:435-45.

14. Lorenz H, Weber E, Omlor A, Walter G, Haass A, Steigerwald $F$, et al. Nachweis von Hirnschädigungen durch Tetrachlorethen. Zentralbl Arbeitsmed Arbeitssh Prophyl Ergonomie 1990;40:355-64.

15. Lundberg I, Michélsen H, Nise G, Hogstedt C, Högberg M, Alfredsson L, et al. Neuropsychiatric function of housepainters with previous long-term heavy exposure to organic solvents. Scand J Work Environ Health 1995;21 suppl 1:44 p.

16. Juntunen J, Matikainen E, Antti-Poika M, Suoranta H, Valle M. Nervous system effects of long-term occupational exposure to toluene. Acta Neurol Scand 1985;72:512-7.

17. Hayakawa K, Kumagai H, Suzuki Y, Furusawa N, Haga T, Hoshi T, et al. MR imaging of chronic alcoholism. Acta Radiol 1992;33:201—6.

18. Torvik A, Lindboe CF, Rogde S. Brain lesions in alcoholics: a neuropathological study with clinical correlations. J Neurol Sci 1982;56:233 - 48 .

19. Gyldensted C. Measurements of the normal ventricular system and hemispheric sulci of 100 adults with computed tomography. Neuroradiology 1977;14:183-92.

20. Fazekas F. Magnetic resonance signal abnormalities in asymptomatic individuals: their incidence and functional correlates. Eur Neurol 1989;29:164-8.

21. Rosenberg NL, Kleinschmidt-DeMasters BK, Davis KA Dreisbach JN, Hormes JT, Filley CM. Toluene abuse causes diffuse central nervous system white matter changes. Ann Neurol 1988;23:611-4.

22. Yamanouchi N, Okada S, Kodama K, Hirai S, Sekine H, Murakami $\mathrm{A}$, et al. White matter changes caused by solvent abuse. Am J Neuroradiol 1995;16:1643-9.

23. Caldemeyer KS, Armstrong SW, George KK, Moran CC, Pascuzzi RM. The spectrum of neuroimaging abnormalities in solvent abuse and their clinical correlation. J Neuroimag 1996;6:167-73.

24. Davis PC, Gray L, Albert M, Wilkinson W, Hughes J, Heyman A, et al. The consortium to establish a registry for Alzheimer's disease (CERAD), part III: reliability of a standardized MRI evaluation of Alzheimer's disease. Neurology 1992 42:1676-80.

Received for publication: 21 October 1998 